\title{
LUTO, NEGAÇÃO, ALUCINAÇÃO: UMA RADIOGRAFIA DO HORROR PSICOLÓGICO NA SÉRIE SERVANT, DE TONY BASGALLOP ${ }^{1}$
}

Oscar Nestarez

Recebido em 27 jan 2020. Oscar Nestarez

Aprovado em 21 fev 2021. Doutorando em Estudos Comparados de Literaturas de Língua Portuguesa pela FFLCH-USP.

Membro e parecerista do Grupo de Pesquisa Produções literárias e culturais para crianças e jovens II (FFLCH-USP).

https://orcid.org/0000-0003-2723-1231

Resumo: 0 presente trabalho pretende investigar os mecanismos e os índices do que se convencionou chamar de "horror psicológico" a partir da série estadunidense Servant. Para tanto, inicialmente se procederá à conceituação do horror como efeito estético, à qual serão relacionados postulados advindos da teoria psicanalítica. Neste primeiro momento serão utilizados, como suporte teórico, excertos dos estudos Horror: A literary history (2016), organizado por Xavier Aldana Reyes, Philosophy of horror, or Paradoxes of the heart (1990), de Noël Carroll, e o ensaio "Horror and the Idea of Everyday Life: On Skeptical Threats in Psycho and The birds" (2010), de Philip J. Nickel, e O infamiliar (2019), de Sigmund Freud. A seguir, será verificado de que forma

1 Título em inglês: "Mourning, denial, hallucination: a radiography of psychological horror in Tony Basgallop's series Servant". 
conceitos advindos da psicanálise contribuem para uma leitura mais aprofundada desse objeto. Isso será feito utilizando-se como corpus a série Servant, na qual se investigará a figuração desses conceitos, seja como topoi, seja como agentes do efeito do horror. Dois textos vão balizar essa hipótese por conta de sua aproximação com os temas centrais da narrativa em questão: o ensaio Luto e melancolia (2011), também de Freud, e o artigo "Objetos transicionais e fenômenos transicionais", contido em $O$ brincar e a realidade (2019), de Donald W. Winnicott.

Palavras-chave: Horror. Carroll. Luto. Objeto transicional. Freud. Winnicott.

Abstract: The present work intends to investigate the mechanisms and the traces of what is conventionally called "psychological horror" in the US Servant series. Initially, a definition of horror as an aesthetic effect will be elaborated, related to concepts from psychoanalytic theory. In this first moment, excerpts from the studies Horror: A literary history (2016), organized by Xavier Aldana Reyes, and Philosophy of horror, or Paradoxes of the heart (1990), by Noël Carroll. Will be used, as well as the essay "Horror and the Idea of Everyday Life: On Skeptical Threats in Psycho and The birds" (2010), by Philip J. Nickel, and Das unheimliche (2019), by Sigmund Freud. Next, it will be verified how concepts from psychoanalysis contribute to a more in-depth reading of this object. This will be done using the Servant series as a corpus, in which the expression of these concepts will be investigated, either as topoi or as agents of the effect of horror. Two texts will guide this hypothesis because of its approximation with the central themes of the narrative in question: the essay Mourning and melancholy (2011), also by Freud, and the article "Transitional objects and transitional phenomena", in Playing and reality (2019), by Donald W. Winnicott.

Keywords: Horror. Carroll. Mourning. Transitional object. Freud. Winnicott. 
Quão avassaladora pode ser a perda de uma pessoa amada? Quão perigosas podem ser as consequências das escolhas realizadas na sequência dessa perda? Tais indagações compõem o núcleo da série Servant, transmitida pelo canal de streaming Apple TV+. São as questões a partir das quais estruturam-se os dez episódios da primeira temporada, cuja estreia ocorreu em novembro de 2019 - a segunda temporada, inaugurada em janeiro de 2021 e também com dez capítulos, está em andamento no momento em que este artigo é escrito. As respostas para essas indagações ainda não nos foram apresentadas; talvez nem o sejam por completo. Mas as hipóteses desenvolvidas pelo criador e roteirista da série, o britânico Tony Basgallop, encontram-se - todas elas - no campo do horror. Ou, ainda, para o que se convencionou denominar "horror psicológico".

Neste artigo, propomo-nos a duas tarefas principais. Inicialmente, investigaremos essa natureza psicológica do horror, compreendendo o efeito estético - e, consequentemente, a estética da recepção de Jauss e Iser - como determinante para a categoria, à qual relacionaremos conceitos advindos da teoria psicanalítica. Para tanto, utilizaremos, como suporte teórico, excertos dos estudos Horror: A literary history ${ }^{2}$ (2016), organizado por Xavier Aldana Reyes, Philosophy of horror, or Paradoxes of the heart ${ }^{3}$ (1990), de Noël Carroll, e o ensaio "Horror and the Idea of Everyday Life: On Skeptical Threats in Psycho and The birds"14 (2010), de Philip J. Nickel, e O infamiliar (2019), de Sigmund Freud. A seguir, verificaremos de que forma esses conceitos podem ser mobilizados 2 Horror: Uma história literária.

3 A filosofia do horror, ou paradoxos do coração.

4 "Horror e a ideia da vida cotidiana: ameaças céticas em Psicose e Os pássaros". 
para uma leitura mais aprofundada da trama da série Servant, seja pela via de topoi, seja figurando como essenciais para a construção da atmosfera e a obtenção do efeito do horror. Lançaremos mão de dois textos para balizar a análise: o ensaio Luto e melancolia (2011), também de Freud, e o artigo "Objetos transicionais e fenômenos transicionais", contido em O brincar e a realidade (2019), de Donald W. Winnicott. Nosso propósito é desmontar e investigar o maquinário do horror desenvolvido por uma série que, desde seu lançamento, vem sendo bem recebida pelo público e pela crítica (Servant obteve média de 7,6 no site Internet Movie Database, ou $\mathrm{IMDB}^{5}$, atualmente uma importante referência de avaliação de narrativas audiovisuais).

De início, cabe apontar que a conceituação do horror como categoria estética (ou artística) é relativamente recente - as primeiras teorias datam de meados da segunda metade do século XX. É o que afirma Aldana Reyes na introdução de Horror: A literary history (2016, British Library): "a segunda metade do século 20 também produziu o mais significativo número de textos sobre horror até então" (2016, p. 14). Os estudos dessa época, em sua maioria anglófonos, concentram-se principalmente no cinema de horror. E ganham ímpeto sobretudo a partir dos anos 1970, quando, na esteira do imenso sucesso comercial experimentado por $O$ exorcista (1973), as produções do gênero nos EUA atraem interesse inédito de público, crítica e, em consequência, mercado. Recebendo enormes quantias de dinheiro, o cinema de horror estabelece-se como uma verdadeira indústria, em um processo que passa a chamar a atenção de pesquisadores dessa linguagem.

5 Disponível em https://www.imdb.com/title/tt8068860/. Acesso em: 20 de jan. de 2021. 
Entretanto, é o campo literário que fornece os alicerces teóricos para a análise aqui proposta. Mais especificamente o já mencionado estudo organizado por Xavier Aldana Reyes. Tratase de uma coletânea de ensaios historiográficos que apresenta um panorama dessa categoria literária por meio da investigação de suas origens e mutações ao longo dos últimos 250 anos. Neste trabalho, interessa-nos a introdução de Reyes ao conjunto de textos, na qual ele propõe uma conceituação das narrativas literárias de horror. $\mathrm{O}$ pesquisador pontua que o próprio termo "horror" advém de um efeito; afinal, sua origem está no verbo latino "horrere", que significa "eriçar" ou "arrepiar". Dessa forma, as narrativas de horror constituem-se como tal pelo efeito causado, ou pela intenção de fazê-lo. Eis a definição ${ }^{6}$ de Reyes:

Amplamente lida e publicada - e diferente de outros gêneros que se amparam mais fortemente em coordenadas históricas e geográficas específicas, como o Western e a ficção-científica -, a ficção de horror é extensivamente definida por suas pretensões afetivas. Em outras palavras, o horror obtém este nome dos efeitos que procura provocar nos leitores ${ }^{7}$. $(2016$, p. 7$)$

O estudioso espanhol salienta que o horror é eminentemente transmidiático, sendo "mais imediatamente associado com a indústria do cinema do que com a literatura" ${ }^{8}$ (REYES, 2016, p. 9). No entanto, ao contrapor a ficção literária de horror às narrativas 6 As traduções de Horror: A literary history, de The Philosophy of horror, or paradoxes of the heart e dos demais textos em língua inglesa são de nossa autoria.

7 Widely read and published - and not like other genres that rely more heavily on specific historical e locational coordinates, such as the Western and the science fiction - horror is largely defined by its affective pretences. Horror takes its name, in other words, from the effects that it seeks to elicit in its readers.

$8[\ldots]$ more readily associated with the film industry than with the literary one. 
audiovisuais, o pesquisador catalão postula que, "diferentemente do cinema, que só é capaz de nos mostrar imagens, a ficção literária nos força a processar informação [...] podendo mais intensamente perturbar a mente de leitores ao engajar-se com suas imaginações" ${ }^{\prime \prime}$ (REYES, 2016, p. 09-10). As consequências dessa perturbação seriam justamente os efeitos de ordem física (principalmente os arrepios), que aqui se propõe vincular à conceituação do horror, ainda que na esfera audiovisual.

Pensamento semelhante é o do filósofo estadunidense Noël Carroll. Ele o exprime e detalha no estudo The philosophy of horror, or paradoxes of the heart, publicado originalmente em 1990 e contendo uma abordagem aristotélica em relação à ficção de horror. Na introdução, Carroll assim define seu ambicioso projeto:

Baseando-me em Aristóteles para propor um paradigma daquilo que pode constituir um gênero artístico, vou oferecer uma explicação do horror em virtude dos efeitos emocionais que se pretende causar na audiência. [...]. Ou seja, ao modo de Aristóteles, vou assumir que o gênero é constituído para produzir um efeito emocional; tentarei isolar esse efeito; e tentarei mostrar como as estruturas, as imagens e as figuras características do gênero arranjam-se para causar a emoção que chamarei de horror artístico. ${ }^{10}(1990$, p. 8)

9 Unlike cinema, which cannot help but show us images, fiction forces us to process information [...] may more readily disturb the minds of readers by engaging with their imagination.

10 Taking Aristotle to propose a paradigm of what the philosophy of an artistic genre might be, I will offer an account of horror in virtue of the emotional effects it is designed to cause in audiences. [...] That is, in the spirit of Aristotle, I will presume that the genre is designed to produce an emotional effect; I will attempt to isolate that effect; and I will attempt to show how the characteristic structures, imagery, and figures in the genre are arranged to cause the emotion that I will call art-horror. 
Mais adiante, o filósofo é categórico: "Trans-artístico e transmidiático, o gênero do horror obtém seu título da emoção que caracteristicamente, ou idealmente, provoca; essa emoção constitui a marca identificadora do horror ${ }^{111}$ "' (CARROLL, 1990, p. 14). Nesse contexto, as personagens nas narrativas em questão exercem papel central, pois é por meio delas que espectadores, leitores ou, mais recentemente, gamers experimentam o referido efeito emocional, ou estético. A propósito, a pesquisadora alemã Doreen Triebel oferece-nos uma oportuna reflexão pela via da empatia no artigo "Manipulating empathic responses in horror fiction"12. Ela defende que "a observação do medo nos outros pode levar um indivíduo a empatizar com uma personagem que se considera estar em perigo" (TRIEBEL, 2014 , p. 6). Assim, o espectador/leitor/gamer sente com e pelas personagens das narrativas que consomem, partilhando com elas as emoções negativas deflagradas por eventos ou agentes do horror.

Pensamento semelhante é o de Noël Carroll. Embora sem mencionar o termo "empatia", o filósofo entende que

[o] horror parece ser um daqueles gêneros nos quais as reações emocionais da audiência, idealmente, correm paralelamente à emoção das personagens. De fato, em obras de horror as reações das personagens frequentemente parecem indicar as reações emocionais das audiências. (CARROLL, 1990, p. 17)

11 The cross-art, cross-media genre of horror takes its title from the emotion it characteristically or rather ideally promotes; this emotion constitutes the identifying mark of horror.

12 "Manipulando respostas empáticas na literatura de horror". 
Mais à frente, Carroll explica que esse pressuposto "permite-nos olhar para as obras de horror em busca de evidências da reação emocional que pretendem engendrar ${ }^{13 \prime \prime}$ (1990, p. 30).

A propósito dos elementos constitutivos das narrativas de horror, e a despeito da elucidativa conceituação, cabem alguns comentários críticos ao estudo do filósofo. Em especial ao difundido entendimento de Carroll de que o agente do horror deve necessariamente ser um monstro, e que esse monstro só pode ser "sobrenatural ou ter uma origem na ficção científica" (1990, p. 15). Essa limitação resultou em questionamentos de outros estudiosos, como Philip J. Nickel, professor de filosofia e ética da Universidade de Tecnologia de Eindhoven. No ensaio "Horror and the Idea of Everyday Life: On Skeptical Threats in Psycho and The birds" (2010), Nickel afirma que o horror tem caráter epistemológico e constitui-se por dois elementos centrais: "(1) Uma aparição do mal sobrenatural ou do monstruoso (inclui-se aí o psicopata que mata monstruosamente); e (2) a intenção de causar pavor, aversão visceral, medo ou espanto no espectador ou no leitor"14 (2010, p. 14).

Ao inserir o elemento humano nesse contexto, Nickel propõe que monstros também sejam "realistas"15 (2010, p. 15) e que participem normalmente de nossa vida cotidiana. Sendo assim, ele se contrapõe diretamente a Carroll, para quem 13 This presupposition, in turn, enables us to look to works of horror themselves for evidence of the emotional response they want to engender.

14 (1) An appearance of the evil supernatural or the monstruous (this includes the psychopath who kills monstruously); and (2) the intentional elicitation of dread, visceral disgust, fear or startlement in the spectator or reader.

15 Realistic. 
"monstros são essencialmente ficcionais, e não algo com que nos preocupemos na vida real"16 (1990, p. 14-15).

Entretanto, a nosso ver, determinar o monstro ou a figura monstruosa (seja ela humana ou sobrenatural) como a única fonte do horror resulta em outro importante impasse. Assim formuladas, as conceituações tanto de Noël Carroll quanto de Philip J. Nickel não contemplariam, por exemplo, a categoria do horror cósmico, na qual os arrepios não têm origem material, e sim existencial. Há, sem dúvida, monstruosidades sobrenaturais de imensa força nas narrativas de H.P. Lovecraft; mas elas irrompem como efeitos colaterais da revelação que sustenta toda a obra lovecraftiana: a de nossa insignificância diante do caos primordial e da imensidão do cosmos. Nesse contexto, não tem mais lugar o maniqueísmo que marca os conflitos das narrativas de horror cujo agente é o monstro; exemplos disso são, entre tantas outras, as narrativas "A cor que caiu do espaço" e "Nas montanhas da loucura". Nelas, já não há um antagonista com intenções e qualidades definidas; as entidades de Lovecraft não pretendem nos aniquilar ou nos aprisionar no inferno, porque sequer têm consciência de nossa existência. Seu mero despertar já implicaria a nossa extinção. Por isso, o fenômeno do horror cósmico não apenas contesta as concepções de Carroll e de Nickel a respeito de histórias assustadoras, como também se afasta dos temas religiosos que, muitas vezes, são as fontes de assombro nessas narrativas. Processo semelhante ocorre com a categoria que se convencionou chamar de horror psicológico (à qual pertence Servant), que não raro têm origens também imateriais - e cujo funcionamento pretendemos clarificar.

$16[\ldots]$ monsters are essentially fictional, not something to be worried about in real life. 
Antes, cumpre destacar o papel assumido pelo receptor nas conceituações do horror aqui apresentadas. Mais especificamente o leitor, dado que vem dos estudos literários o arcabouço teórico que nos permite conjugar tais concepções em torno de um efeito. Para tal, reportamo-nos à estética da recepção, corrente de pensamento concebida e proposta na década de 1960 pelo teórico alemão Hans Robert Jauss e consolidada, no final dos anos 1970, com a contribuição de seus conterrâneos Wolfgang Iser e Hans Gumbrecht, entre outros. Embora as teorizações da chamada Escola de Constança já se distanciem no tempo e apresentem certo desgaste, é necessário retomá-las, ainda que resumidamente, para ampliar a análise aqui proposta.

À época, a formulação de Jauss confrontava teorias formalistas e marxistas, refutando o que ele considerava o "circuito fechado" (1988, p. 266) de uma estética de reprodução, fundamentado na dicotomia "autor-livro". Desta forma, afirmava o alemão, a literatura se despojava "de uma condição inerente à sua própria natureza de fenômeno estético e à sua função social: a dimensão do efeito produzido por uma obra" (1988, p. 266-267). Em suma, Jauss defende a retomada da fruição estética como elemento central da experiência literária e artística, fundamentada na aisthesis (sensação). Sugeriu, assim, alterar o centro de gravidade da criação literária, do eixo "autor-livro" para a configuração "autor-livro-leitor". Nesta pesquisa, propomos ampliar tal conjugação, de modo a abranger também uma narrativa audiovisual em série como Servant.

Retomando até aqui: a ficção de horror define-se pelo efeito estético ou emocional que pretende provocar, e as causas disso podem ser variadas, indo além do monstro e de 
suas derivações. Contudo, essa definição ainda é problemática, posto que a categorização apenas pela via do efeito constitui um critério necessariamente subjetivo. Dentro desse parâmetro, um determinado livro somente se enquadraria no gênero caso quem o leu sentisse horror ou emoções correlatas - o que exigiria pesquisas de dimensões e frequência inimagináveis. Assim, torna-se necessário acrescentar, a esse pressuposto, a constituição da narrativa, a sua própria organização. Pois como nos recorda Edgar Allan Poe (2011) no seminal ensaio "A filosofia da composição", também de tonalidade aristotélica, a produção de um efeito estético é resultado. É consequência de um minucioso processo de elaboração retórica, em que cada elemento deve ser cuidadosamente situado e encaixado, como a peça de um poderoso maquinário. No caso da ficção de horror, há a primazia do efeito em questão, de modo que essas narrativas se singularizam em relação a outras vertentes que, quando aliançadas ao horror, trabalham tais reações em menor medida, como a ficção científica, as distopias, a fantasia (ou sua ramificação sombria, a dark fantasy), e mesmo o drama. Depreende-se, evidentemente, que todo efeito resulta de um trabalho cuidadoso com a linguagem utilizada - sendo ela composta por vocabulário, temas e estruturas próprios, que se acumulam e se renovam desde o século XVIII. No caso das narrativas audiovisuais, entram em jogo elementos como desenho de som, cenários, escolha de elenco, entre vários outros.

A propósito, cabem ainda algumas palavras a respeito das relações entre a ficção de horror e suas reconhecidas matrizes, o fantástico e o gótico. A conceituação aqui apresentada permite- 
nos enxergar uma autonomia do horror em relação às narrativas fantásticas, posto que a estratégia para se obter o efeito definidor possa prescindir do elemento sobrenatural ou inexplicável, e, consequentemente, da hesitação todoroviana. Da mesma forma, o horror torna-se independente da matriz histórico-cultural das narrativas góticas na medida em que a fonte de horríveis eventos já não se encontra apenas em um passado que ameaça retornar (um dos procedimentos determinantes para tais obras, de acordo com o pesquisador brasileiro Júlio França [2017, p. 18]), mas também na atualidade. Outra marca distintiva do horror em relação ao gótico é o diálogo intersemiótico: narrativas audiovisuais e literárias permanecem em intensa relação de mutualismo, o que proporciona uma constante atualização de estratégias e a renovação do repertório para a obtenção do efeito em questão.

Realizadas essas considerações a respeito do horror, verifiquemos de que forma a psicanálise pode contribuir tanto para a compreensão quanto para a intensificação de tal fenômeno. Nesse sentido, nenhuma conceituação é mais esclarecedora do que Das unheimliche, de Sigmund Freud. Publicado pela primeira vez em 1919, o artigo apresenta uma reflexão estética do fundador da psicanálise a partir da literatura. Freud se detém em obras "que dizem respeito ao aterrorizante, ao que suscita angústia e horror" (2019, p. 29, grifo nosso) para investigar as origens do efeito por ele nomeado como unheimlich. O termo alemão tem etimologia complexa: "heimlich" significa "doméstico, familiar, pertencente à casa", mas o prefixo "un" inverte esses conceitos, tornando desconhecido aquilo que era absolutamente o contrário. 
A edição utilizada nesta pesquisa é relativamente recente no Brasil; nela, o termo é traduzido como "infamiliar". Os tradutores Gilson lannini e Pedro Heliodoro Tavares assim justificam a escolha, contribuindo também para a acepção do conceito cunhado por Freud:

O unheimlich é uma negação que se sobrepõe ao heimlich apreendido tanto positiva quanto negativamente: é, portanto, uma reduplicação dessa negação, que acentua seu caráter angustiante e assustador. A palavra em português que melhor desempenha esse aspecto parece ser "infamiliar": do mesmo modo, ela acrescenta uma negação a uma palavra que abriga tanto o sentido positivo de algo que conhecemos e reconhecemos quanto o sentido negativo de algo que desconhecemos. (FREUD, 2019, p. 10-11, nota dos tradutores do livro)

Com efeito, logo no início do ensaio, o fundador da psicanálise estabelece o unheimlich/infamiliar como "não conhecido" (2019, p. 33). Mais à frente, Freud postula que o "Infamiliar seria tudo o que deveria permanecer em segredo, oculto, mas que veio à tona" (2019, p. 45); "nada tem realmente de novo ou de estranho, mas é algo íntimo à vida anímica desde muito tempo e que foi afastado pelo processo de recalcamento" (2019, p. 85).

Assim se destaca, no ensaio, o retorno daquilo que há muito era perfeitamente conhecido pelo sujeito, mas que por algum motivo torna-se alheio, estranho, infamiliar. Para Freud, é justamente esse movimento pendular a causa das sensações de estranheza e de horror vinculadas a narrativas como "O homem da areia", que constitui o principal corpus do artigo, e tantas outras.

A teoria freudiana já nos conduz ao território de Servant, uma vez que a série assume, desde o início, o compromisso com o horror 
de natureza psicológica. Isso fica evidente no primeiro episódio, intitulado "Renascido". Por meio dele, somos apresentados aos personagens que compõem o núcleo da trama: o jovem casal Turner, formado pela bem-sucedida jornalista Dorothy e pelo renomado chef experimental Sean (interpretados por Lauren Ambrose e Toby Kebbell), e a ainda mais jovem babá Leanne Grayson (Nell Tiger Free), que foi contratada para cuidar de Jericho, o filho recémnascido dos dois. A sequência inicial, em que Leanne chega à casa dos Turner, oferece a medida e o tom da narrativa, pois ela se dá em uma noite chuvosa e a câmera movimenta-se lentamente pelos cômodos escurecidos da grande residência. Assim, instila-se não apenas tensão, mas uma sensação de que algo não está certo. Com efeito, Dorothy parece exageradamente entusiasmada com a chegada da babá; seu comportamento destoa do marido, que se mostra falsamente interessado pelo evento. Quando Leanne entra em cena, a atmosfera se adensa ainda mais: enigmática e monossilábica, de olhar fixo, ela surge como um espectro, ou um autômato, e porta-se como se guardasse um segredo. Mas o segredo, nesse momento, pertence aos Turner. Jericho é, na verdade, um boneco reborn, artefato bastante similar a um bebê recém-nascido. A nosso ver, a descoberta provoca imediatamente horror por seu caráter "infamiliar", pois aquilo que está no berço é reconhecível e ao mesmo tempo estranho; por um breve instante, sentimos a vertigem, o espanto diante do desconhecido.

A existência do falso Jericho é logo esclarecida no mesmo episódio, quando Sean, aproveitando que a esposa saíra para trabalhar, explica a situação para Leanne. O verdadeiro bebê havia morrido treze semanas após o nascimento, Dorothy entrara 
em choque e a família decidira, com o auxílio de profissionais de saúde, adotar medidas para ajudá-la a superar o trauma. $\mathrm{O}$ boneco e consequentemente a babá compõem esse sistema de defesa, 0 qual é mantido em total discrição: apenas o marido, o pai e o irmão de Dorothy, além da terapeuta dela, sabem da fatalidade. Depois da explicação, Sean pergunta se Leanne tem alguma dúvida, e se surpreende com a resposta dela: "Vou levar Jericho para passear", diz a babá, acariciando ternamente o boneco. Ao final desse episódio inaugural, outra reviravolta: o marido encontra, no berço, um bebê de verdade.

Está dado o contexto em que se desenvolverá a história durante a primeira temporada. Pode-se dizer que, em Servant, a narrativa ocorre em dois planos. O primeiro, e mais evidente, é composto pela rotina do casal e da babá, sendo que Leanne se revela cada vez mais estranha e, em consequência, ameaçadora. Nesse quesito, ela parece figurar como um monstro sutil, ainda que sua história e suas intenções permaneçam ocultas - apenas Sean parece se dar conta das características bizarras da moça, já que Dorothy logo se afeiçoa a ela pelo carinho e o amor dedicados a "Jericho". Isso inquieta ainda mais o marido: teria a babá trazido aquele outro bebê? No intuito de continuar preservando a esposa (que sequer notou a diferença entre a criança e o boneco), ele evita abordá-la para debater o mistério. Então, convoca Julian (Rupert Grint), seu cunhado e cúmplice no esquema de proteção da esposa, para investigar Leanne. $\mathrm{E}$ as descobertas que fazem vão acentuando a tensão geral.

Entretanto, é no segundo plano da narrativa, aquele implícito, que encontramos os elementos deflagradores de um horror 
profundo. Afinal, todo o "circo" se arma para auxiliar Dorothy a superar o luto de uma tragédia que só será explicada no penúltimo e poderoso episódio da primeira temporada, intitulado "Jericho" e dirigido por M. Night Shyamalan (que também produz a série). No ensaio Luto e melancolia, publicado originalmente em 1917, Freud reflete sobre a natureza desse estado psíquico que sucede à perda, contrapondo-o à melancolia e assim descrevendo-o:

A prova da realidade mostrou que o objeto amado já não existe mais e agora exige que toda a libido seja retirada de suas ligações com esse objeto. Contra isso se levanta uma compreensível oposição; em geral se observa que o homem não abandona de bom grado uma posição da libido, nem mesmo quando um substituto já se lhe acena. Essa oposição pode ser tão intensa que ocorre um afastamento da realidade e uma adesão ao objeto por meio de uma psicose alucinatória de desejo. (2011, p. 49, grifo nosso)

Ora, é exatamente o que ocorre a Dorothy na série. Trata-se de uma intensa oposição à inexistência do objeto amado, ou à prova de realidade. Mais adiante, o fundador da psicanálise postula que

o normal é que vença o respeito à realidade. Mas sua incumbência não pode ser imediatamente atendida. Ela será cumprida pouco a pouco com grande dispêndio de tempo e de energia de investimento, e enquanto isso a existência do objeto de investimento é psiquicamente prolongada. (2011, p. 49)

Fiando-se nisso, e no entendimento de que o luto "será superado depois de algum tempo e que é considerado inadequado e até mesmo prejudicial perturbá-lo" (FREUD, 2011, p 47), Sean, 
Julian e Natalie, a terapeuta/cinesiologista (Jerrika Hinton), esperam que a enlutada supere o trauma. Entretanto, essa possibilidade fica cada vez mais distante. Por meio do boneco, a existência de Jericho na vida da mãe vai sendo prolongada. A oposição/negação aprofunda-se, assim como a psicose alucinatória. Com efeito, ela alucina que embala seu bebê, que o aninha, que o leva para passear; só não o amamenta porque sente dores intensas nos seios, mas tira leite com o auxílio de uma bomba. E a chegada de Leanne intensifica esse processo, posto que a babá trata primeiramente o boneco como de fato um recémnascido, e depois age da mesma forma com o misterioso bebê que surge na narrativa, sem aparentar qualquer inquietação. Assim, permanece a expectativa - profundamente perturbadora - de que Dorothy possa "acordar" a qualquer momento, e acentua-se a ameaça diante da especulação do que eventualmente aconteça após o despertar.

Outro conceito que nos permite clarificar a natureza do horror em Servant é o de objetos transicionais, proposto pelo pediatra e psicanalista britânico Donald Woods Winnicott. A teoria está apresentada no artigo "Objetos transicionais e fenômenos transicionais", de 1951; no texto, Winnicott questiona a definição basilar da psicanálise segundo a qual o indivíduo constitui-se de uma unidade com uma membrana limitadora entre um exterior e um interior. Para ele, o enunciado duplo (subjetivo-objetivo) não é suficiente, havendo uma terceira parte da vida do ser humano que é composta pelo período em que "o bebê usa o punho e os dedos para estimular a zona erógena oral" (WINNICOTT, 2019, p. 13) e aquele em que ele se apega a um objeto especial, como 
bonecas, ursinhos ou pedaços de tecido. Os objetos ou fenômenos transicionais correspondem, assim, à "área intermediária da experiência entre o polegar e o ursinho, entre o erotismo oral e a verdadeira relação do objeto" (2019, p. 15); trata-se do "uso de objetos que não fazem parte do corpo do bebê, mas ainda não são totalmente reconhecidos como pertencentes à realidade externa" (2019, p. 15). Desta forma, tais objetos operam em um estado intermediário entre a incapacidade e a crescente capacidade do bebê de reconhecer e aceitar a realidade (2019, p. 16); configuram a primeira posse do "não eu" (2019, p. 15), a área entre o subjetivo e aquilo que é objetivamente percebido. Essa transição gera angústia e frustração, sobretudo pelo afastamento natural da mãe (pela via do desmame, por exemplo); e o bebê atribui sentido a objetos transicionais, amparando-se neles para suportar a alteração.

Aqui, propomos um deslocamento dessa conceituação. É nossa intenção atribuir, ao boneco reborn, a função de objeto transicional, mas que nesse caso auxilia Dorothy a atravessar o período da psicose alucinatória do desejo. Ou seja, um recurso que permita a ela retornar do estado intensamente subjetivo à percepção objetiva, um mecanismo que a ajude a aceitar a prova de uma realidade na qual seu filho não existe mais. Contudo, novamente ocorre o oposto: ela não dá sinais de que esteja realizando essa passagem, e o objeto transicional acaba operando como elemento de assombro, como uma lembrança recorrente de seu estado patológico. Além disso, conforme afirmamos, as cenas em que o boneco é mostrado são passíveis de despertar um fugaz, porém saliente efeito de "infamiliaridade", posto que ele remete a algo muito conhecido, mas que ao mesmo tempo não o é. Nesse sentido, 
o objeto relaciona-se à boneca Olímpia, de "O homem da areia", conforme entendida por Freud em $O$ infamiliar. Todo o processo de alienação de Dorothy se agrava ao tornar-se evidente que ela não diferencia o boneco do bebê (supostamente) levado por Leanne para a casa dos Turner - um episódio semelhante ao vivenciado por Natanael no conto de E.T.A. Hoffmann.

Direcionemos agora o enfoque da análise para Sean. Note-se que, assim configurado, o enredo de Servant acaba por oprimir e isolar o marido. Com efeito, durante os primeiros episódios, Sean é a personagem supostamente ancorada na realidade - ou seja, nossas reações emocionais tendem a correr mais paralelamente às suas, como estabeleceu Noël Carroll em relação à concomitância de emoções em uma narrativa de horror. É Sean o principal espelho de nossos sentimentos na trama, é ele o nosso veículo para o horror, que vai se cumprindo à medida que o chef constata não apenas a desconexão da esposa em relação à realidade, mas também os mistérios envolvendo a figura da babá. Julian, seu cunhado, acompanha-o nesse contexto, sendo o responsável por realizar a investigação de Leanne com o auxílio de Roscoe (Phillip James Brannon), um detetive "informal" que é, na verdade, funcionário do RH da empresa do irmão de Dorothy - a relação entre ambos configura um inesperado alívio cômico na narrativa. E o trabalho em equipe dá frutos: os dois descobrem que Leanne Grayson morreu, ao lado do pai e da mãe, em um incêndio na casa da família, fato que acentua a complexidade da história. Sean e Julian acabam por concluir que a babá roubou a identidade da moça morta, assim como o bebê que levou para a casa dos Turner. 
Tudo se torna ainda mais inquietante no sexto episódio, intitulado "Chuva", quando somos apresentados a um suposto tio de Leanne, George (Boris McGiver). Ele aparece subitamente na casa dos Turner durante uma noite de tempestade. Sean está fora, e Dorothy, bastante apegada à babá e sequiosa de conhecer mais sobre a vida dela, convida a sinistra figura para jantar. Aqui, temos a primeira manifestação de uma evidente monstruosidade na narrativa, posto que do tio emana inegável ameaça, constituída por suas maneiras bizarras (comer com a mão, espremer um pedaço de frango para drená-lo etc.), por sua expressão malévola e por seus trajes funéreos. Ele declara a intenção de levar Leanne embora, mas a babá é convencida por Dorothy a confrontá-lo; o tio George então parte, dizendo que da próxima vez trará a tia May (Alison Elliott), a quem Leanne "não consegue dizer não". A chegada dessas personagens deflagra um novo ramo narrativo, que, no último episódio da primeira temporada, acaba por lançar alguma luz no passado da babá: tio George e tia May aparentemente lideram um culto religioso a que Leanne pertencia; os dois a resgataram e cuidaram dela após o incêndio e a morte dos pais, e reaparecem para buscá-la. Permeando tudo, ainda há eventos a indicarem alguma espécie de poder paranormal de Leanne - por exemplo, as rachaduras na parede causadas por ela e a estranha perda do paladar de Sean, aparentemente também obra dela. Até aqui, tanto os traços sobrenaturais quanto a obsessão da babá por Jericho, bem como a origem do novo bebê, permanecem inexplicados.

Por fim, cabem algumas palavras sobre o espaço em Servant. Toda a narrativa se passa no interior da casa dos Turner - um sofisticado tríplex que corresponde ao locus horrendus (ou "lugar 
horrível") das narrativas góticas, em cuja trama os espaços amaldiçoados ocupavam posição central. O termo opõe-se ao locus amoenus (lugar ameno), paisagem idealizada e pacífica presente na poesia amorosa em geral e, com maior incidência, na poesia bucólica. Ambas as expressões foram herdadas do arcadismo e referem-se a um dos tópicos centrais do romantismo. Na gênese dessa última vertente, castelos, abadias, masmorras e outras construções comumente associadas ao medievo predominavam como loci horrendi. A partir de certo momento na historiografia literária, e principalmente com a ascensão da classe burguesa, coube às residências ocupar tal função, e é esse o caso na narrativa em questão. A casa dos Turner representa o espaço demarcado e assombrado pela morte de um bebê recém-nascido. Ao mesmo tempo, é o território íntimo de um casal que acaba invadido por figuras implícita ou explicitamente ameaçadoras, sempre na esteira dessa tragédia. Não à toa, os cômodos são frequentemente escuros, e o cuidadoso desenho de som da série dá destaque a rangidos, pancadas, ecos e outros ruídos geralmente associados a espaços assombrados. Dessa forma, o cenário contribui significativamente para a obtenção do efeito do horror; e alguns cômodos, em especial, destacam-se por configurarem uma extensão da personalidade das personagens. É o caso da adega, no porão, onde Sean e Julian reúnem-se para discutir e tomar decisões sobre a investigação - um espaço subterrâneo correspondendo à vida paralela que o marido deve levar por conta da condição da esposa. Outro exemplo é o quarto de Leanne, que ela decora com o rigor e a simplicidade de um claustro, mas tornado sinistro por um papel de parede com estranhos motivos silvestres. Já a ampla e bem equipada cozinha 
configura-se como espaço híbrido e até vibrante, pois é lá que frequentemente se dão os encontros entre as personagens.

À guisa de conclusão, postulamos que desse conjunto de elementos resulta um território bastante favorável à manifestação do horror, conforme compreendido por Reyes e Carroll. No primeiro plano da narrativa - aquele imediato, do cotidiano do casal -, os assombros e arrepios correspondem principalmente a aspectos visuais, muitas vezes de natureza grotesca (como exemplos, citamos as cenas com o boneco reborn e Sean queimando a mão para descobrir se perdera totalmente a sensibilidade, depois recortando as bolhas na pele com uma tesoura). Ainda no primeiro plano, temos graus diferentes de implícita monstruosidade - mais leve, no caso da babá, e mais intensa em se tratando do tio George e da tia May. Leanne assume, também, a qualidade de autômato, remetendo, assim como o boneco/bebê Jericho, a um tópos recorrente no horror e à Olímpia de "O homem da areia" conforme lida por Freud. Já no plano mais amplo da narrativa, perdura a expectativa do "despertar" de Dorothy como acontecimento capaz de implodir tudo, em uma espécie de cataclismo íntimo; e há o boneco figurando como objeto transicional "invertido", simbolizando essa ameaça. Com efeito, ocorrem momentos em que o despertar da personagem quase acontece: breves e esparsas passagens ao longo da narrativa, nas quais ela se encontra prostrada, olhando para o vazio, imersa em melancolia; mas Dorothy logo é trazida de volta não para a realidade, e sim para a alucinação que se constitui como realidade. Abrigando essa tensa e dramática trama, há os espaços cuidadosamente elaborados para acentuar os efeitos 
pretendidos, além do clima frequentemente chuvoso e noturno a perdurar pela maior parte dos episódios. Servant constituise, assim, como notável exemplo de construção narrativa cujo epicentro é o efeito estético do horror, cujo funcionamento, a nosso ver, pode ser clarificado e compreendido com o amparo de conceitos advindos da psicanálise.

\section{REFERÊNCIAS}

CARROL, Noël. The philosophy of horror, or paradoxes of the heart. New York: Routledge, 1990.

FRANÇA, Júlio. O sequestro do gótico no Brasil. In: FRANÇA, Júlio; COLUCCI, Luciana. As Nuances do Gótico: do Setecentos à atualidade. Rio de Janeiro: Bonecker, p. 111-124, 2017.

FREUD, Sigmund. (2019). O Infamiliar [Das Unheimliche] - edição comemorativa bilíngue. Tradução de Romero Freitas, Ernani Chaves e Pedro Heliodoro Tavares. São Paulo: Autêntica, 2019.

FREUD, Sigmund. Luto e melancolia. Tradução de Marilene Carone. São Paulo: Cosac Naify, 2011.

JAUSS, H. R. apud FIGURELLI, Roberto. Hans Robert Jauss e a Estética da Recepção. Revista Letras. Curitiba, n. 37, p. 265-285, 1988. Disponível em: https:// revistas.ufpr.br/letras/article/view/19243/12535. Acesso em: 27 dez. 2020.

NICKEL, Philip J. Horror and the Idea of Everyday Life: On Skeptical Threats in Psycho and The Birds. In: FAHY, Thomas (Org.). The Philosophy of Horror. Lexington: The University Press of Kentucky, p.14-32, 2010.

POE, Edgar Allan. A filosofia da composição. Tradução de Léa Viveiros de Castro. Rio de Janeiro: 7Letras, 2011.

REYES, Xavier Aldana. Introduction: What, Why and When is Horror Fiction?. In: REYES, Xavier Aldana (Ed.). Horror: A literary history. Londres: British Library, 2016.

TODOROV, Tzvetan. Introdução à Literatura Fantástica. Tradução de Maria Clara C. Castello. 2. ed. São Paulo: Perspectiva, 1992. 
TRIEBEL, Doreen. Manipulating empathic responses in horror fiction. In: KATTELMAN, Beth HODALSKA, Magdalena (Orgs.). Frightful witnessing: the rhetoric and (re)presentation of fear, horror and terror. Oxford: InterDisciplinary Press, 2014.

WINNICOTT, Donald W. O brincar e a realidade. Tradução de Breno Longhi. São Paulo: Ubu editora, 2019. 